\title{
CHEMISTRY
}

\section{ОПРЕДЕЛЕНИЕ МИКРОЭЛЕМЕНТНОГО СОСТАВА НЕКОТОРЫХ МИНЕРАЛЬНЫХ ВОД ГРУЗИИ}

\author{
Гогичаишвили Бела Арменовна, доктор химических наук, профессор, Государственный \\ Университет Акакия Церетели, \\ Дидбаридзе Изольда Сардионовна, доктор химических наук, профессор, Государственный \\ Университет Акакия Церетели, \\ Брегадзе Нестан Левановна, докторант Технического университета Грузии, \\ Махвиладзе Маиа Гелановна, доктор химических наук, Государственный Университет \\ Акакия Церетели
}

2. Кутаиси. Грузия

DOI: https://doi.org/10.31435/rsglobal_ws/30042019/6468

\section{ARTICLE INFO}

Received: 16 February 2019

Accepted: 21 April 2019

Published: 30 April 2019

\section{KEYWORDS}

Amfolits,

Microelements,

Macroelements

\begin{abstract}
Among the chemical elements contained in small quantities in mineral waters, of interest are trace elements that have a certain biological activity. According to the method developed by us, the content of copper, nickel, zinc, cobalt, chromium and manganese in certain mineral waters of Western Georgia was determined. The obtained data on the content of trace elements in mineral waters are of practical value, information about the trace element composition will contribute to the further study of these waters in hydrogeological, hydrochemical and balneological aspects.
\end{abstract}

Citation: Гогичаишвили Б. А., Дидбаридзе И. С., Брегадзе Н. Л., $\quad$ Махвиладзе М. Г. $\quad$ (2019) Determination of Trace Elements in Some Mineral Waters of Georgia. World Science. 4(44), Vol.1. doi: 10.31435/rsglobal_ws/30042019/6468

Copyright: (C) 2019 Гогичаишвили Б. А., Дидбаридзе И. С., Брегадзе Н. Л., Махвиладзе М. Г. Тhis is an open-access article distributed under the terms of the Creative Commons Attribution License (CC BY). The use, distribution or reproduction in other forums is permitted, provided the original author(s) or licensor are credited and that the original publication in this journal is cited, in accordance with accepted academic practice. No use, distribution or reproduction is permitted which does not comply with these terms.

Несмотря на большую историю минеральных вод Грузии, содержание микроэлементов в них исследовано недостаточно. Различия же макроэлементном составе исследуемые вод не всегда дают возможность объяснить то или иное бальнеологическое воздействие этих вод. Для объяснения причин лечебного действия грузинских минеральных вод большое значение может знание микроэлементного состава этих вод.

Объектом исследования было выбраны подземные минеральные воды, расположенные на Грузинской глыбе. Грузинская глыба занимает наиболее пониженное в гипсометрическом отношении положение на территории Грузии. В тектоническом отношении она характеризуется сравнительно спокойным залеганием толщ юрских, меловых и третичных образовании над кристаллическим субстратом. Мощная толща осадочных пород содержит региональные водоносные горизонты нижнего и верхнего мела, миоцена и плиоцена, которые в благоприятных тектонических структурах слагают артезианские бассейны.

Общей характерной чертой минеральных вод Грузинской глыбы является отсутствие в них углекислого газа. Среди довольно разнообразных гидрохимических типов, встречающихся в этой зоне, наиболее существенны хлоридные натриевые, кальциевые и натриево-кальциевые, сульфатные натриевые и кальциевые, а также воды более сложного состава. Многие из минеральных вод Грузинской глыбы термальны. Были отобраны пробы тринадцати 
месторождении, приуроченных к Грузинской глыбе, а также пробы минеральной воды Сортуани, выведенной скважиной на территории геотектонического района Южного склона большого Кавказа, примыкающего с севера к Грузинской глыбе. Для всех проб было проведено определение ионно-солевого состава по схеме, соответствующей схеме сокращенного анализа воды НИИ курортологии и физиотерапии Грузии.

При разработке методики определения микроэлементов $\mathrm{Zn}, \mathrm{Cu}, \mathrm{Co}, \mathrm{Ni}, \mathrm{Cr}, \mathrm{Mn}$ в минеральных водах нами в качестве сорбентов были использованы винилпиридиновый амфолит АНКБ-2 и иминодиацетатные амфолит АНКБ-10. Для определения оптимальных условии концентрирования наряду с изучением влияния сорбента исследовалось также и влияние кислотности растворов и объемов проб, пропускаемых через адсорбент [1]. Был найден оптимальный элюемт для десорбции и установлены режимы сорбции и десорбции.

По разработанной нами методике было определено содержание меди, никеля, цинка, кобальта, хрома и марганца в некоторых минеральных водах Западной Грузии. Полученные результаты приведены в таблице 1 .

Таблица 1. Среднее содержание микроэлемент в некоторый водах Западной Грузии

\begin{tabular}{|c|c|c|c|c|c|c|c|}
\hline \multirow[t]{2}{*}{ № } & \multirow{2}{*}{$\begin{array}{c}\text { Наименование } \\
\text { минеральной води и ее } \\
\text { химический состав } \\
\end{array}$} & \multicolumn{6}{|c|}{ концентраций микроэлемент в г/л } \\
\hline & & $\mathrm{Zn}$ & $\mathrm{Cu}$ & $\mathrm{Ni}$ & $\mathrm{Co}$ & $\mathrm{Cr}$ & Mn \\
\hline 1. & Симонети бур. 2 & $1.9 \cdot 10^{-5}$ & $3.8 \cdot 10^{-6}$ & $1.2 \cdot 10^{-5}$ & следи & $4.5 \cdot 10^{-7}$ & следи \\
\hline 2. & Цхалтубо ист.3. & $1.6 \cdot 10^{-5}$ & $3.4 \cdot 10^{-6}$ & $9.9 \cdot 10^{-6}$ & Не обн. & Не обн. & $4.4 \cdot 10^{-6}$ \\
\hline 3. & Менджи бур.1. & $1.3 \cdot 10^{-5}$ & $2.2 \cdot 10^{-6}$ & $4.6 \cdot 10^{-6}$ & Не обн. & Не обн. & Не обн. \\
\hline 4. & Цаищи ист. & $1.6 \cdot 10^{-5}$ & $3.2 \cdot 10^{-6}$ & $8.2 \cdot 10^{-6}$ & Не обн. & $7.6 \cdot 10^{-7}$ & Не обн. \\
\hline 5. & Сортуани бур. & $5.4 \cdot 10^{-5}$ & $5.7 \cdot 10^{-6}$ & $6.7 \cdot 10^{-6}$ & следи & $5.3 \cdot 10^{-6}$ & $4.1 \cdot 10^{-6}$ \\
\hline 6. & Уцера (разлив) & $5.4 \cdot 10^{-5}$ & $8.8 \cdot 10^{-6}$ & $5.0 \cdot 10^{-6}$ & Не обн. & $1.0 \cdot 10^{-5}$ & $5.6 \cdot 10^{-6}$ \\
\hline 7. & Саирме (разлив) & $5.4 \cdot 10^{-5}$ & $1.4 \cdot 10^{-6}$ & $6.5 \cdot 10^{-6}$ & Не обн. & $1.3 \cdot 10^{-5}$ & $1.0 \cdot 10^{-5}$ \\
\hline 8. & Набеглави (разлив) & $4.9 \cdot 10^{-5}$ & $8.8 \cdot 10^{-6}$ & $4.1 \cdot 10^{-6}$ & Не обн. & $4.4 \cdot 10^{-6}$ & $2.3 \cdot 10^{-5}$ \\
\hline
\end{tabular}

Для оценки полученных данных целесообразно было бы сравнить среднее содержание микроэлементов в минеральных водах, определенное по разработанной нами методике, с имеющимися данными о содержании этих микроэлементов в морской и речной водах и среднее содержание этих элементов в исследованных минеральных водах. В таблице 2 приводятся среднее содержанные микроэлементов исследованных минеральных вод.

Таблица 2. Среднее содержание микроэлементов в различных видах природных вод мг/л

\begin{tabular}{|l|l|l|l|l|l|l|}
\hline Тип воды & \multicolumn{1}{c|}{$\mathrm{Zn}$} & \multicolumn{1}{c|}{$\mathrm{Cu}$} & \multicolumn{1}{c|}{$\mathrm{Ni}$} & \multicolumn{1}{c|}{$\mathrm{Co}$} & $\mathrm{Cr}$ & \multicolumn{1}{c|}{$\mathrm{Mn}$} \\
\hline Морская вода & $1 \cdot 10^{-2}$ & $3 \cdot 10^{-3}$ & $2 \cdot 10^{-3}$ & $5 \cdot 10^{-4}$ & $5 \cdot 10^{-5}$ & $2 \cdot 10^{-3}$ \\
\hline Речная вода & $2 \cdot 10^{-2}$ & $5 \cdot 10^{-3}$ & $5 \cdot 10^{-3}$ & $1 \cdot 10^{-3}$ & - & - \\
\hline Минеральные воды & $3.1 \cdot 10^{-2}$ & $3.2 \cdot 10^{-3}$ & $8.4 \cdot 10^{-3}$ & $3.6 \cdot 10^{-4}$ & $4.4 \cdot 10^{-3}$ & $5.2 \cdot 10^{-3}$ \\
\hline
\end{tabular}

Из данных таблице 2 следует, что содержание $\mathrm{Zn}, \mathrm{Cu}, \mathrm{Co}, \mathrm{Ni}$ и $\mathrm{Mn}$ в минеральных водах и того же порядка, что и в морской и речкой вода, только хром в минеральной воде обнаружено больше, чем в морской. Для оценки влияния природы минеральной воды на содержание микроэлементов сопоставлялись минеральные воды, приуроченные к двум геотектоническим единицам южному склону Большего Кавказа и Аджаро-Триалетской складчатой системе. Таблице 3 приведено среднее содержание микроэлементов в соответствии с региональным положением минеральных вод таблица3.

Таблица 3. Среднее содержание микроэлементов в углекислых водах различных регионов мг/л

\begin{tabular}{|l|l|l|l|l|l|}
\hline $\begin{array}{l}\text { Региональная } \\
\text { приуроченность } \\
\text { улекислых вод }\end{array}$ & \multicolumn{1}{|c|}{$\mathrm{Zn}$} & \multicolumn{1}{|c|}{$\mathrm{Ni}$} & $\mathrm{Cr}$ & $\mathrm{Mn}$ \\
\hline $\begin{array}{l}\text { Южный склон } \\
\text { большого Кавказа }\end{array}$ & $4.3 \cdot 10^{-2}$ & $6.1 \cdot 10^{-3}$ & $5.8 \cdot 10^{-3}$ & $1.0 \cdot 10^{-2}$ & $4.9 \cdot 10^{-3}$ \\
\hline $\begin{array}{l}\text { Аджара-триалетская } \\
\text { складчатая система }\end{array}$ & $5.2 \cdot 10^{-2}$ & $5.5 \cdot 10^{-3}$ & $7.9 \cdot 10^{-3}$ & $8.7 \cdot 10^{-3}$ & $9.8 \cdot 10^{-3}$ \\
\hline
\end{tabular}


Следует отметить более высокое содержание меди и хрома в минеральных водах южного склона и преимущество вод Аджаро-Триалетской складчатой системы по содержанию цинка, никеля и марганца. Такое различие в содержании микроэлементов является в определенной мере отражением литологических условии в различных геотектонических районах.

Полученные данные о содержании микроэлементов в минеральных водах имеют практическую ценность, т.к. сведения о микроэлементном составе минеральных вод в сочетании с изучением распределения этих элементов в породах и с исследованием бальнеологических особенностей минеральных вод, будут способствовать дальнейшему изучению этих вод в гидрогеологическом, гидрохимическом и бальнеологическом аспектах.

\section{ЛИТЕРАТУРА}

1. Б. Гогичаишвили, И. Дидбаридзе, Н. Брегадзе. О некоторых условия сорбции микроэлентов на амфолитах при их определении в минеральных водах. SCIENCE, RESEARCH, DEVELOPMENT TECHNICS AND TECHNOLOGY \#5. Barcelona.

2. Б. Гогичаишвили, И. Дидбаридзе. Выбор оптимальных условии хроматографического концентрировання $\mathrm{Fe}$, Со и $\mathrm{Ni}$ с целью определение в природных водах. Химический журнал Грузии. Т.15, №1. 2015.

3. Г.Г. Джиннчарадзе, Б.А. Гогичаишвили, Н.В. Бокучава, Д.Г. Джиннчарадзе. Физико - химические аспекты рацинального использования Цхалтубских минеральных вод. Известия национальной Академии наук Грузии. Серия химическая том 35 №4. 2009.

4. Б. Гогичаишвили, И. Дидбаридзе, Н. Брегадзе. Определение микроэлементного состава некоторых минеральных водах Грузии с применением хроматографического концентрирования. Известия национальной Академии наук Грузии. Серия химическая том 43 №1.2017.

5. К.М.Олшанова, М.А.Полтапова. Практикум по хроматографическому анализу. М. 1970. 